\title{
Physical Localization of a Locus from Agropyron cristatum Conferring Resistance to Stripe Rust in Common Wheat
}

\author{
Zhi Zhang ${ }^{1,+}$ [D , Liqiang Song ${ }^{2,+}$, Haiming Han ${ }^{1}$, Shenghui Zhou ${ }^{1}$, Jinpeng Zhang ${ }^{1}$, \\ Xinming Yang ${ }^{1}$, Xiuquan $\mathrm{Li}^{1}$, Weihua Liu ${ }^{1}$ and Lihui $\mathrm{Li}^{1, *}$ \\ 1 National Key Facility for Crop Gene Resources and Genetic Improvement, Institute of Crop Sciences, \\ Chinese Academy of Agricultural Sciences, Beijing 100081, China; zhangzhihkd@126.com (Z.Z.); \\ hanhaiming@caas.cn (H.H.); zhoushenghui@caas.cn (S.Z.); zhangjinpeng@caas.cn (J.Z.); \\ yangxinming@caas.cn (X.Y.); lixiuquan@caas.cn (X.L.); liuweihua@caas.cn (W.L.) \\ 2 Center for Agricultural Resources Research, Institute of Genetics and Developmental Biology of Sciences, \\ Shijiazhuang 050022, China; songliqiang.1988@163.com \\ * Correspondence: lilihui@caas.cn; Tel.: +86-010-621-86670 \\ + These authors contributed equally to this work.
}

Received: 26 September 2017; Accepted: 8 November 2017; Published: 13 November 2017

\begin{abstract}
Stripe rust, caused by Puccinia striiformis f. sp. tritici (Pst), is one of the most destructive diseases of wheat (Triticum aestivum L.) worldwide. Agropyron cristatum (L.) Gaertn. $(2 n=28$, PPPP), one of the wild relatives of wheat, exhibits resistance to stripe rust. In this study, wheat-A. cristatum $6 \mathrm{P}$ disomic addition line 4844-12 also exhibited resistance to stripe rust. To identify the stripe rust resistance locus from $A$. cristatum $6 \mathrm{P}$, ten translocation lines, five deletion lines and the $\mathrm{BC}_{2} \mathrm{~F}_{2}$ and $\mathrm{BC}_{3} \mathrm{~F}_{2}$ populations of two wheat- $A$. cristatum $6 \mathrm{P}$ whole-arm translocation lines were tested with a mixture of two races of Pst in two sites during 2015-2016 and 2016-2017, being genotyped with genomic in situ hybridization (GISH) and molecular markers. The result indicated that the locus conferring stripe rust resistance was located on the terminal $20 \%$ of $6 \mathrm{P}$ short arm's length. Twenty-nine 6P-specific sequence-tagged-site (STS) markers mapped on the resistance locus have been acquired, which will be helpful for the fine mapping of the stripe rust resistance locus. The stripe rust-resistant translocation lines were found to carry some favorable agronomic traits, which could facilitate their use in wheat improvement. Collectively, the stripe rust resistance locus from A. cristatum $6 \mathrm{P}$ could be a novel resistance source and the screened stripe rust-resistant materials will be valuable for wheat disease breeding.
\end{abstract}

Keywords: stripe rust; $A$. cristatum; common wheat; translocation lines

\section{Introduction}

Stripe rust, caused by Puccinia striiformis f. sp. tritici (Pst), is one of the most devastating and widespread diseases of wheat (Triticum aestivum L.) around the world [1-3]. Stripe rust has become a major threat to wheat production, causing yield losses of 5-25\% [4,5]. In recent years, new virulent Pst races appeared in a short period of time so that many wheat varieties were ineffective against prevalent races [6]. Therefore, there is a need to screen new stripe rust resistance genes for broadening the wheat gene pool and providing new potential resistance genes for the wheat breeding of stripe rust resistance.

Wide hybridization is an efficient way of transferring beneficial resistance genes to common wheat. Different resistance genes from distant genera, such as $Y r 9$ from Secale cereal [7,8], Pm21 from Haynaldia villosa [9] and YrH9020 from Psathyrostachys huashanica [10], have been transferred to 
common wheat, and were effective in enhancing the disease resistance of wheat. The disease-resistant wheat-alien species derivative lines will be used as new wheat resources for breeding new resistant varieties.

The genus Agropyron (Gaertn.) belongs to the tribe Triticeae and is based on the P genome. Agropyron cristatum (L.) Gaertner, the most common species, has diploid $(2 n=2 x=14, \mathrm{PP})$, tetraploid $(2 n=4 x=28$, PPPP) and hexaploid $(2 n=6 x=42$, PPPPPP) forms. Tetraploid A. cristatum carries yield-related genes [11-13] and biotic and abiotic resistance genes [14-16], which is a favorable genetic resource for the genetic improvement of wheat. With the accomplishment of the wide hybridization of common wheat and A. cristatum [17-19], many desirable genes from A. cristatum have been transferred into common wheat. Wu et al. [20] found that A. cristatum 6P carried multi-kernel gene(s) [20]. Lu et al. [21] localized the higher thousand-grain weight locus on 7PS arm using translocation lines and deletion lines. Li et al. [22] and Copete et al. [23] confirmed that 2PL arm carried powdery mildew resistance gene(s), meanwhile Copete et al. [23] also found that 6PL arm carried powdery mildew resistance gene(s) using the addition lines. Ochoa et al. [16] have acquired the leaf rust-resistant wheat- $A$. cristatum translocation line.

To map alien desirable genes, a series of wheat-alien translocation lines and deletion lines were produced to construct the physical map. Qi et al. [24] constructed the physical mapping of Haynaldia villosa $6 \mathrm{~V}$ using one spontaneous deletion line and two deletion lines induced by irradiation. Ashida et al. [25] created chromosomal breaks in the offspring of a $5 \mathrm{H}$ addition line induced by the gametocidal chromosome and constructed the physical map of barley chromosome $5 \mathrm{H}$. Wheat-A. cristatum translocation lines and deletion lines have been developed through the irradiation of wheat- $A$. cristatum disomic addition lines, and high-resolution physical maps of $A$. cristatum $2 \mathrm{P}, 6 \mathrm{P}$ and 7P have been constructed [21,22,26-29]. The physical maps and the introgression lines can provide a solid foundation for the exploration and utilization of elite genes from the wide relatives of wheat.

In this study, wheat- $A$. cristatum $6 \mathrm{P}$ derivative lines and the populations were used to map the stripe rust resistance locus from $A$. cristatum $6 \mathrm{P}$ to the specific chromosomal region. The resistance locus could be a novel stripe rust-resistant source and the screened resistant materials will be valuable for wheat disease breeding.

\section{Result}

\subsection{Evaluation of Stripe Rust Resistance of Wheat-A. cristatum 6P Disomic Addition Line 4844-12}

During 2015-2016 and 2016-2017, a mixture of prevalent physiological races (CYR32 and CYR33) was utilized to infect wheat- $A$. cristatum 6P disomic addition line 4844-12, common wheat "Fukuhokomugi" and common wheat "Huixianhong" in Yangling (Shaanxi province, China) and Xinxiang (Henan province, China). Among these materials, the line 4844-12 was highly resistant to stripe rust, while the controls Fukuhokomugi and Huixianhong were highly susceptible (Figure 1). Therefore, the locus conferring stripe rust resistance was derived from A. cristatum chromosome 6P. 


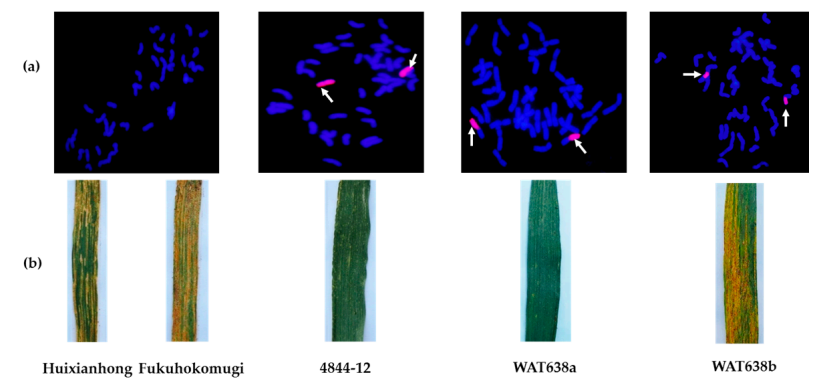

Figure 1. (a) GISH detection for the control Fukuhokomugi and the lines 4844-12, WAT638a and WAT638b containing intact 6P, 6PS and 6PL, respectively. A. cristatum chromosomal segments were in red, while wheat chromosomes were in blue strained by DAPI. (b) Evaluation of stripe rust of Huixianhong, Fukuhokomugi, 4844-12, WAT638a and WAT638b.

\subsection{Molecular Cytogenetic Analysis and Chromosomal Arm Localization of the Locus Conferring Resistance to} Stripe Rust

A series of wheat- $A$. cristatum $6 \mathrm{P}$ translocation lines and deletion lines have been developed through irradiation of the addition line 4844-12 [26,29]. Ten translocation lines and five deletion lines were used to map the stripe rust resistance locus. All of these lines contained a pair of segments of A. cristatum 6P detected by GISH (Figure 2). A. cristatum 6P-specific STS molecular markers were used to trace different chromosomal segments of $A$. cristatum $6 \mathrm{P}$ to confirm the constitutions of $\mathrm{P}$ chromatin in each line (Figure 3).
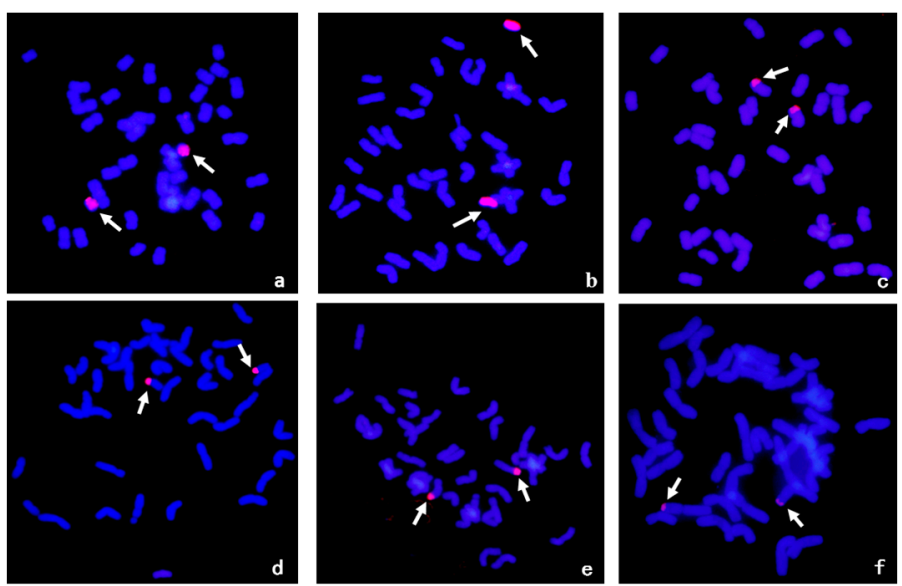

Figure 2. GISH patterns of wheat- $A$. cristatum $6 \mathrm{P}$ homozygous strains. A. cristatum chromosomes were in red, while wheat chromosomes were in blue strained by DAPI. (a) del21; (b) del19a; (c) WAT641a; (d) WAT657; (e) WAT648; and (f) WAT646. The homozygous materials carried a pair of chromosomal segments. 


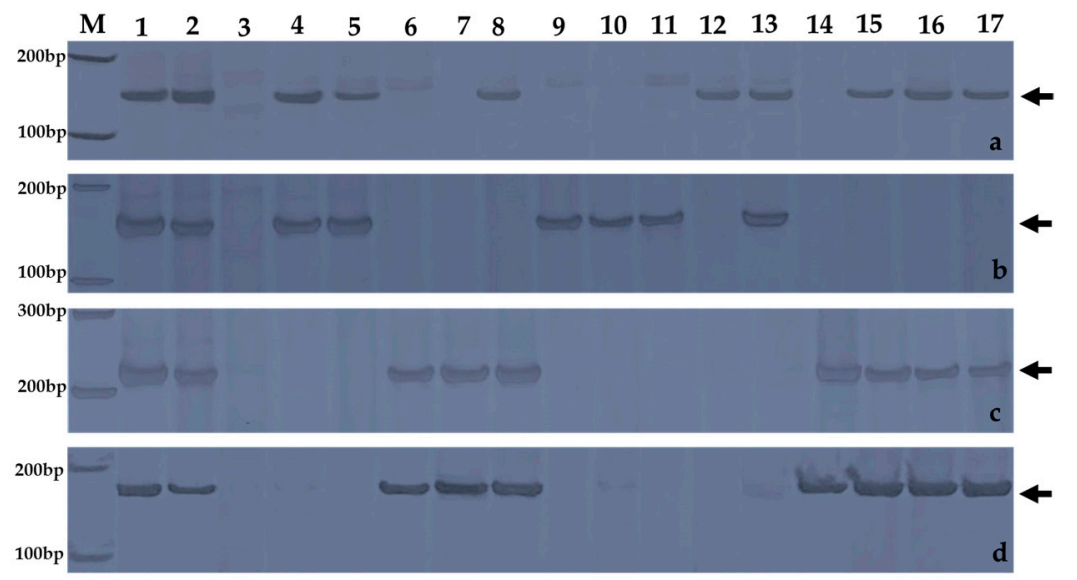

Figure 3. Amplification patterns of wheat- $A$. cristatum homozygous materials using $6 \mathrm{P}$-specific STS markers: (a) Agc4527; (b) Agc37790; (c) Agc21670; (d) Agc2970. Lanes: M, DNA marker I; 1, A. cristatum accession Z559; 2, 4844-12; 3, Fukuhokomugi; 4, WAT639b; 5, WAT638a; 6, WAT639a; 7, WAT638b; 8, WAT644; 9, WAT655; 10, WAT648; 11, WAT641a; 12, WAT657; 13, del21; 14, del20; 15, del29; 16, del23; 17, del19a. Arrows indicated the diagnostic bands.

To identify the arm carrying the resistance locus, four wheat- $A$. cristatum $6 \mathrm{P}$ whole-arm translocation lines (WAT639b, WAT638a, WAT639a and WAT638b) and two 6P ditelosomic addition lines (del21 and del20) were tested using a mixture of the Pst races in two sites. Among them, all lines carrying chromosome arm 6PS were resistant; all lines carrying chromosome arm 6PL were susceptible (Table 1, Figure 1). This identifies the short arm of $6 \mathrm{P}$ as the carrier of the resistance locus.

Table 1. Evaluation of stripe rust resistance of homozygous materials in two seasons.

\begin{tabular}{ccccc}
\hline \multirow{2}{*}{ Materials } & 6P Segment Size & Stripe Rust Response & \multicolumn{2}{c}{ No. Detected of Each Replicate } \\
\cline { 4 - 5 } & & & Xinxiang & Yangling \\
\hline WAT639b & 6PS arm & $\mathrm{R}$ & 40 & 40 \\
WAT638a & 6PS arm & $\mathrm{R}$ & 40 & 40 \\
del21 & 6PS arm & $\mathrm{R}$ & 40 & 30 \\
WAT639a & 6PL arm & $\mathrm{S}$ & 40 & 40 \\
WAT638b & 6PL arm & $\mathrm{S}$ & 40 & 40 \\
del20 & 6PL arm & $\mathrm{S}$ & 40 & 30 \\
WAT657 & 6PS (0.00-0.15) & $\mathrm{S}$ & 40 & 40 \\
WAT644 & 6PS (0.00-0.20) +6PL & $\mathrm{S}$ & 40 & 40 \\
del19a & 6PS (0.00-0.15) +6PL & $\mathrm{S}$ & 40 & 30 \\
del23 & 6PS (0.00-0.45)+6PL & $\mathrm{S}$ & 40 & 30 \\
del29 & 6PS (0.00-0.81)+6PL & $\mathrm{R}$ & 40 & 40 \\
WAT641a & 6PS (0.53-1.00) & $\mathrm{R}$ & 40 & 40 \\
WAT648 & 6PS (0.59-1.00) & $\mathrm{R}$ & 40 & 40 \\
WAT655 & 6PS (0.81-1.00) & $\mathrm{R}$ & 40 & 40 \\
WAT646 & 6PS (0.86-1.00) &
\end{tabular}

6P segment size: The comparison of the length of 6P segments and intact 6P arm. The position of the centromere was considered as 0 , while the terminal end of the 6PS/6PL arm was considered as 1 . The letters $R$ and $S$ in "Stripe rust response" column indicated plants were resistant and susceptible, respectively.

The $\mathrm{BC}_{2} \mathrm{~F}_{2}$ and $\mathrm{BC}_{3} \mathrm{~F}_{2}$ populations of WAT639a and WAT639b were constructed to confirm the resistance locus on chromosome 6PS. P genome-specific molecular markers [30] were used to detect the populations (Figure 4). In the $\mathrm{BC}_{2} \mathrm{~F}_{2}$ population (2015-2016 season) of the line WAT639b, 22 plants carried 6PS arm, which were resistant; while 32 did not carried 6PS, which were susceptible. In the $\mathrm{BC}_{3} \mathrm{~F}_{2}$ population (2016-2017 season) of the line WAT639b, 97 plants carried 6PS arm, which were resistant; while 52 did not carry 6PS, which were susceptible (Table 2). Chi squared $\left(\chi^{2}\right)$ tests for 
independence showed that stripe rust resistance was significantly affected by the 6PS arm. In the populations of the line WAT639a, no matter whether the plants contained the 6PL arm or not, all were susceptible, suggesting that there was no correlation between stripe rust resistance and the 6PL arm. Therefore, the 6PS arm surely carried the resistance locus.

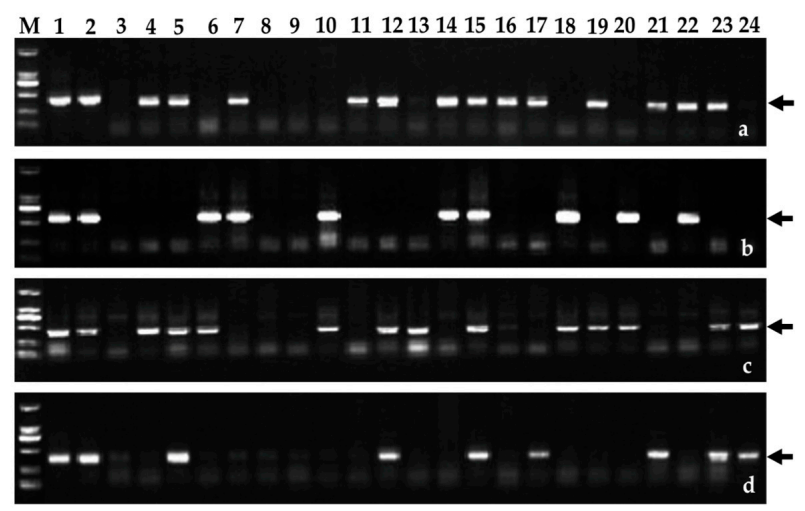

Figure 4. Amplification patterns of the $\mathrm{BC}_{3} \mathrm{~F}_{2}$ population of wheat-A. cristatum $6 \mathrm{P}$ short-arm translocation lines WAT639b using $\mathrm{P}$ genome-specific molecular markers, including (a) AcPR6; (b) AcPR7; (c) AcPR3a; and (d) AcPR2a. Lanes: M, DL2000 DNA Marker; 1, Z559; 2, 4844-12; 3, Fukuhokomugi; 4-24, the partial plants of the WAT639b population. Arrows indicated the diagnostic bands.

Table 2. Response to stripe rust in populations of $6 \mathrm{P}$ whole-arm translocation lines.

\begin{tabular}{|c|c|c|c|c|c|c|c|}
\hline \multirow[t]{2}{*}{ Materials } & \multirow[t]{2}{*}{ Type } & \multicolumn{2}{|c|}{$2015-2016\left(\mathrm{BC}_{2} \mathrm{~F}_{2}\right)$} & \multirow[t]{2}{*}{ Total } & \multicolumn{2}{|c|}{$2016-2017\left(\mathrm{BC}_{3} \mathrm{~F}_{2}\right)$} & \multirow[t]{2}{*}{ Total } \\
\hline & & $6 \mathrm{P}+$ & $6 \mathrm{P}-$ & & $6 \mathrm{P}-$ & $6 \mathrm{P}-$ & \\
\hline Huixianhong & & & $S(30)$ & 30 & & S (40) & 40 \\
\hline Fukuhokomugi & & & $S(30)$ & 30 & & S (40) & 40 \\
\hline 4844-12 & & $\mathrm{R}(30)$ & $S(0)$ & 30 & R (40) & $S(0)$ & 40 \\
\hline WAT639b * & 6PS.7AL & $\mathrm{R}(22)$ & $S(32)$ & 54 & $\mathrm{R}(97)$ & $S(52)$ & 149 \\
\hline WAT639a & 7AS.6PL & $S(41)$ & S (29) & 70 & S (135) & S (54) & 189 \\
\hline
\end{tabular}

"6P+" indicated the plants contained A. cristatum $6 \mathrm{P}$ chromatin, while "6P-" indicated the plants did not contain $6 \mathrm{P}$ chromatin. The letters $\mathrm{R}$ and $\mathrm{S}$ indicated plants were resistant and susceptible, respectively. ${ }^{*}$ Chi-square statistics: $p$ value $<0.01$.

\subsection{Chromosomal Segmental Localization of the Stripe Rust Resistance Locus}

Six translocation lines (WAT657, WAT644, WAT641a, WAT648, WAT655 and WAT646) and three terminal deletion lines (del19a, del23 and del29) were applied to further map the resistance locus to the smaller segment of 6PS arm. The lines WAT657, WAT644, del19a, del23 and del29 were highly susceptible to stripe rust (Figure 5, Table 1). They contained the segments 6PS (0.00-0.15), $6 \mathrm{PS}(0.00-0.20)+6 \mathrm{PL}, 6 \mathrm{PS}(0.00-0.15)+6 \mathrm{PL}, 6 \mathrm{PS}(0.00-0.45)+6 \mathrm{PL}$ and $6 \mathrm{PS}(0.00-0.81)+6 \mathrm{PL}$, respectively, suggesting that the stripe rust resistance locus was not on 6PS (0.00-0.81). The terminal translocation lines WAT641a, WAT648, WAT655 and WAT646 carried the segments 6PS (0.53-1.00), 6PS (0.59-1.00), 6PS (0.81-1.00) and 6PS (0.86-1.00), respectively, which were highly resistant to stripe rust (Figure 5). Among the resistant lines, the leaves of WAT646 carried few spores of Pst. Therefore, we localized the resistance locus on the bin 6PS (0.81-1.00) of WAT655 (Figure 6). 


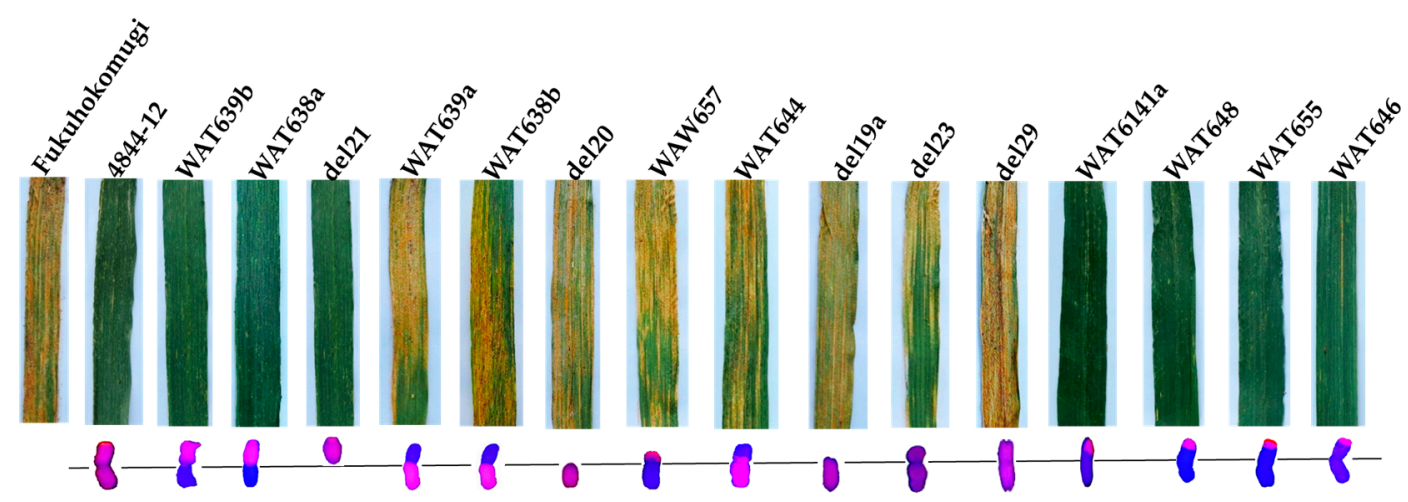

Figure 5. Evaluation of stripe rust resistance of wheat- $A$. cristatum $6 \mathrm{P}$ derivatives. GISH patterns: $6 \mathrm{P}$ chromosomal segments were in red, while wheat chromosomal segments were in blue strained by DAPI.

\subsection{Evaluation of Agronomic Traits of the Stripe Rust-Resistant Translocation Lines}

The spike agronomic traits of six wheat-A. cristatum 6P translocation lines (WAT638a, WAT639b, WAT641a, WAT648, WAT655 and WAT646) conferring stripe rust resistance were evaluated at $\mathrm{BC}_{2} \mathrm{~F}_{3}$ progeny, including spike length, spikelet number per spike, kernel number per spikelet, grain number per spike and thousand-grain weight in this study (Table 3). The seeds of the lines WAT638a, WAT639b, WAT648, WAT655 and WAT646 displayed longer and wider size than that of Fukuhokomugi (Figure 7), so that these translocation lines exhibited higher thousand-grain weights. Compared to Fukuhokomugi, the lines WAT655 and WAT646 showed higher grain number per spike, contributed by the higher spikelet number per spike based on Duncan's multiple-range test.

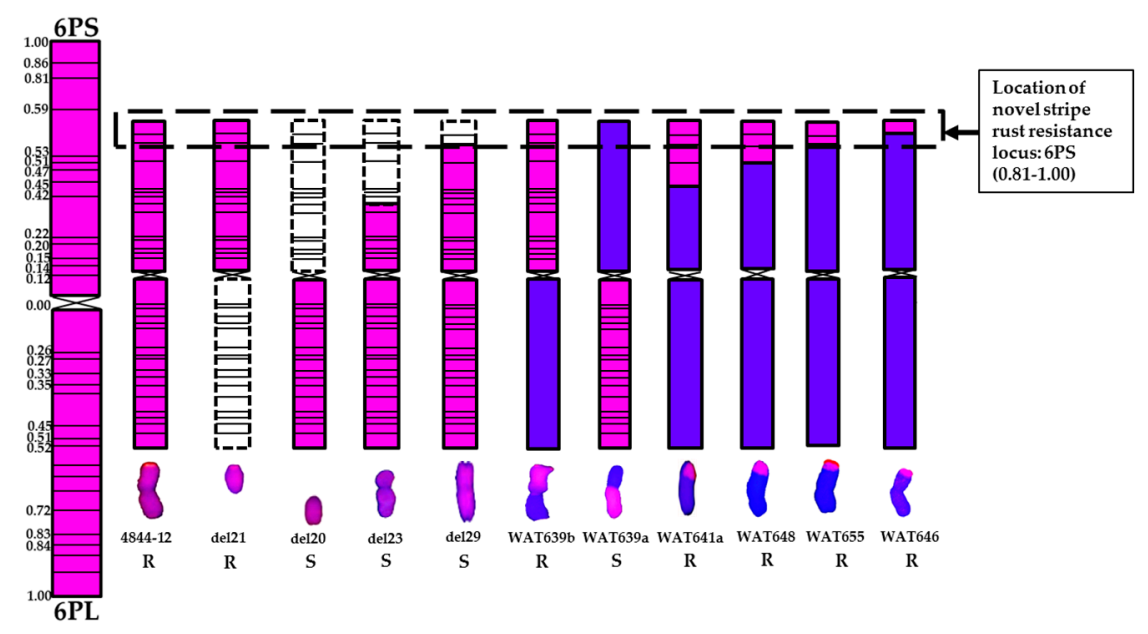

Figure 6. Chromosomal localization of the novel stripe rust resistance locus from A. cristatum $6 \mathrm{P}$ and chromosome diagrams of the deleted and the translocated 6P chromosomes. The left map showed that the diagram of $A$. cristatum chromosome $6 \mathrm{P}$, which was modified in the physical map of $A$. cristatum $6 \mathrm{P}$ as described by Song et al. [29]. Pink and blue colors represented A. cristatum and wheat chromosomal segments, respectively. Dotted line boxes indicated the missing segments of $6 \mathrm{P}$ chromosome. The letters $\mathrm{R}$ and $\mathrm{S}$ indicated materials were resistant and susceptible, respectively. 


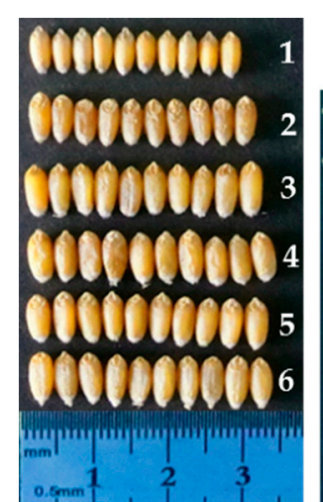

(a)

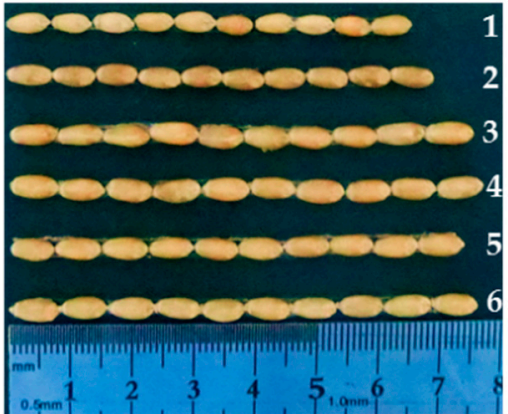

(b)

Figure 7. Morphologies of (a) grain width and (b) grain length. 1, Fukuhokomugi; 2, 4844-12; 3, WAT638a; 4, WAT648; 5, WAT655; and 6, WAT646. 
Table 3. Agronomic traits for stripe rust-resistant translocation lines and their parents in 2017.

\begin{tabular}{|c|c|c|c|c|c|c|}
\hline Materials & Type & Spike Length $(\mathrm{cm})$ & $\begin{array}{l}\text { Spikelet Number per } \\
\text { Spike }\end{array}$ & $\begin{array}{c}\text { Kernel Number per } \\
\text { Spikelet }\end{array}$ & $\begin{array}{c}\text { Grain Number per } \\
\text { Spike }\end{array}$ & $\begin{array}{c}\text { Thousand-Grain } \\
\text { Weight (g) }\end{array}$ \\
\hline $4844-12$ & & $10.35 \pm 0.69$ & $23.36 \pm 2.27$ & $4.48 \pm 0.51$ & $72.96 \pm 5.79$ & $37.74 \pm 0.46$ \\
\hline Fukuhokomugi & & $10.24 \pm 0.84$ & $18.76 \pm 1.42$ & $4.20 \pm 0.41$ & $55.08 \pm 5.85$ & $32.98 \pm 1.40$ \\
\hline WAT639b & 6PS.7AL & $10.08 \pm 0.98$ & $19.48 \pm 1.58$ & $4.22 \pm 0.68$ & $57.00 \pm 3.62$ & $35.16 \pm 3.47^{*}$ \\
\hline WAT641a & 7A-6PS & $9.50 \pm 1.15$ & $17.50 \pm 1.91$ & $4.25 \pm 0.50$ & $48.50 \pm 7.93$ & $33.08 \pm 3.52$ \\
\hline WAT648 & 5DS.5DL-6PS & $10.05 \pm 0.99$ & $20.44 \pm 1.65$ * & $3.77 \pm 0.94$ & $56.22 \pm 5.40$ & $46.92 \pm 4.14^{* *}$ \\
\hline WAT655 & 6DS.6DL-6PS & $11.26 \pm 0.86 *$ & $21.28 \pm 1.50$ * & $4.07 \pm 0.45$ & $64.38 \pm 6.65^{* *}$ & $38.38 \pm 4.84^{* *}$ \\
\hline
\end{tabular}

${ }^{* *}$ denoted significant differences from Fukuhokomugi by Duncan's multiple-range test at the probability levels of $p=0.05$ and $p=0.01$, respectively (analysis of variance by SAS 9.2) 


\section{Discussion}

Broadening the genetic base of common wheat by transferring resistance genes from wide relatives may enhance the chance of achieving adequate resistance against stripe rust. Wheat-A. cristatum $6 \mathrm{P}$ disomic addition line 4844-12 was immune to the infection with stripe rust (CYR32 and CYR33). Six translocation lines WAT638a, WAT639b, WAT641a, WAT648, WAT655 and WAT646 were highly resistant to stripe rust. Among these lines, WAT646 was slightly different from others in the response to stripe rust (Figure 5). The leaves of WAT646 carried few spores of Pst. There may be two reasons for this difference. Firstly, WAT655 was a homoeologous translocation line, because the 6P segment was translocated to 6D, while the 6P segment of WAT646 was translocated to 1B [29]. Compensating translocations between homoeologous wheat and alien segments are favorable and beneficial for wheat improvement [31], so that WAT655 may display better complementary than WAT646. Secondly, the 6PS (0.81-1.00) of WAT655 was larger than the 6PS (0.86-1.00) of WAT646, so the $6 \mathrm{P}$ segment of WAT655 may contain more resistance genes than that of WAT646. Therefore, we localized the resistance locus on the 6P segment of WAT655. Collectively, the six translocation lines exhibit high resistance to stripe rust and can be the new stripe rust-resistant resources for resistance breeding.

A. cristatum, as a favorable genetic resource, carried various disease resistance genes $[16,22,23]$. The leaf rust resistance locus from $A$. cristatum has been transferred to common wheat [16]. Copete et al. [23] utilized the addition lines to confirm A. cristatum 2PL and 6PL carried powdery mildew resistance gene(s). Song et al. [26] mapped a leaf rust resistance locus of A. cristatum on 6PS (0.81-1.00) using A. cristatum 6P deletion lines. In this study, the stripe rust resistance locus was found to be located on 6PS (0.81-1.00). The leaf rust resistance locus and the stripe rust resistance locus from A. cristatum $6 \mathrm{P}$ were coincidently located on the same chromosomal segment. The translocation lines (WAT639b, WAT638a, WAT648 and WAT655) were resistant to stripe rust in this research, and they also were resistant to leaf rust. Therefore, the resistance locus mapped on 6PS (0.81-1.00) may be a broad-spectrum resistance locus, and we speculate that there may be one favorable disease resistance gene cluster on 6PS (0.81-1.00).

Molecular marker technique has been a considerably efficient and convenient method to detect the alien genomic component. A series of P genome-specific STS markers were designed through EST sequences of $A$. cristatum transcriptome sequences [32]. Song et al. [20] mapped 255 STS markers on the physical map of A. cristatum 6P. These markers were used to trace the 6P segments of translocation lines and deletion lines in this research. Twenty-nine STS markers were mapped on the region of the resistance locus. These 6P-specific STS markers will be useful for screening disease-resistant materials in wheat breeding, which will provide a basis for fine mapping of the wheat rust resistance locus in future work.

In recent years, many wheat varieties have lost resistance against stripe rust due to the deficiency of resistance genes and variation of Pst races. The emergence of two prevalent physiological races (CYR32 and CYR33) have resulted in the loss of stripe rust resistance of more varieties. However, only a few resistance genes conferred still resistance to stripe rust in common wheat, such as Yr5, Yr10, Yr15, $Y r 24 / Y r 26$ and $Y r 50$ [33-36]. Therefore, continuous exploration of new stripe rust resistance genes, particularly wide-spectrum genes, will be imperative, which will enhance the diversity of stripe rust resistance gene. Transferring stripe rust resistance genes from the wild relatives to common wheat has been an effective approach to enhance the agronomic performance of wheat [37]. Wheat-rye 1BL-1RS translocation line possesses the stripe rust resistance gene $Y_{r} 9[7,8]$. The stripe rust resistance genes from emmer wheat, such as $Y r 15$ [38], $Y r 35 / L r 52$ [39] and $Y r 30 / S r 2$ [40], have been transferred to common wheat. In this research, the stripe rust resistance locus of A. cristatum $6 \mathrm{P}$ has been transferred into common wheat in translocation line form. The stripe rust resistance locus is a broad-spectrum resistance locus, which can be used for genetic improvement of wheat as a new resistance source. The stripe rust-resistant lines with favorable agronomic traits can be utilized in wheat breeding as new disease-resistant wheat germplasms. The small segmental lines (WAT648, WAT655 and WAT646) 
will be as the basis for further exploring the stripe rust resistance locus through RNA-Sequence in future research.

In summary, the novel stripe rust resistance locus from A. cristatum $6 \mathrm{P}$ was located on the region 6PS (0.81-1.00) using homozygous strains and the populations. The stripe rust-resistant translocation lines will be used for wheat disease-resistant breeding as new germplasms and for fine mapping of the novel stripe rust resistance locus as the basic materials.

\section{Materials and Methods}

\subsection{Plant Materials}

The plant materials, Triticum aestivum cv. Fukuhokomugi ( $2 n=6 x=42$, AABBDD), A. cristatum accession Z559 ( $2 n=4 x=28$, PPPP, from Xinjiang, China), wheat- $A$. cristatum $6 \mathrm{P}$ disomic addition line 4844-12 ( $2 n=44)$, five $\mathrm{M}_{5}$ A. cristatum 6P homozygous deletion lines (del21, del20, del19a, del23 and del29) [26], ten $\mathrm{BC}_{2} \mathrm{~F}_{3}$ wheat- $A$. cristatum $6 \mathrm{P}$ homozygous translocation lines (WAT639b, WAT638a, WAT639a, WAT638b, WAT657, WAT641a, WAT648, WAT655, WAT646 and WAT644) and the $\mathrm{BC}_{2} \mathrm{~F}_{2}$ and $\mathrm{BC}_{3} \mathrm{~F}_{2}$ populations of WAT639a and WAT639b, were utilized in this study. The detailed information of translocation lines and deletion lines was shown in Table 4 . Wheat-A. cristatum 6P disomic addition line 4844-12 was acquired by distant hybridization between the A. cristatum accession "Z559" and common wheat variety "Fukuhokomugi". All of the plant materials were preserved at the Center of Crop Germplasm Resources Research in the Institute of Crop Science, Chinese Academy of Agricultural Sciences (Beijing, China).

Table 4. The detailed information of plant materials.

\begin{tabular}{|c|c|c|c|c|}
\hline Materials & Zygosity & Progeny & Type & 6P Segment Size \\
\hline del21 & Homozygous & $\mathrm{M}_{5}$ & 6PS telosomic & 6PS arm \\
\hline del20 & Homozygous & $\mathrm{M}_{5}$ & 6PL telosomic & $6 \mathrm{PL}$ arm \\
\hline del19a & Homozygous & $\mathrm{M}_{5}$ & $6 \mathrm{PS}$ terminal deletion & $6 \mathrm{PS}(0.00-0.15)+6 \mathrm{PL}$ \\
\hline del23 & Homozygous & $\mathrm{M}_{5}$ & 6PS terminal deletion & $6 \mathrm{PS}(0.00-0.45)+6 \mathrm{PL}$ \\
\hline del29 & Homozygous & $\mathrm{M}_{5}$ & 6PS terminal deletion & $6 \mathrm{PS}(0.00-0.81)+6 \mathrm{PL}$ \\
\hline WAT639b & $\begin{array}{l}\text { Homozygous } \\
\text { Heterozygous }\end{array}$ & $\begin{array}{c}\mathrm{BC}_{2} \mathrm{~F}_{3} \\
\mathrm{BC}_{2} \mathrm{~F}_{2}, \mathrm{BC}_{3} \mathrm{~F}_{2}\end{array}$ & 6PS.7AL & 6PS arm \\
\hline WAT638a & Homozygous & $\mathrm{BC}_{2} \mathrm{~F}_{3}$ & 6PS.6AL & $6 \mathrm{PS}$ arm \\
\hline WAT639a & $\begin{array}{l}\text { Homozygous } \\
\text { Heterozygous }\end{array}$ & $\begin{array}{c}\mathrm{BC}_{2} \mathrm{~F}_{3} \\
\mathrm{BC}_{2} \mathrm{~F}_{2}, \mathrm{BC}_{3} \mathrm{~F}_{2}\end{array}$ & 7AS.6PL & $6 \mathrm{PL}$ arm \\
\hline WAT638b & Homozygous & $\mathrm{BC}_{2} \mathrm{~F}_{3}$ & 6AS.6PL & 6PL arm \\
\hline WAT657 & Homozygous & $\mathrm{BC}_{2} \mathrm{~F}_{3}$ & 6AS.6PS & 6PS (0.00-0.15) \\
\hline WAT641a & Homozygous & $\mathrm{BC}_{2} \mathrm{~F}_{3}$ & 7A-6PS & 6PS (0.53-1.00) \\
\hline WAT648 & Homozygous & $\mathrm{BC}_{2} \mathrm{~F}_{3}$ & 5DS.5DL-6PS & 6PS (0.59-1.00) \\
\hline WAT655 & Homozygous & $\mathrm{BC}_{2} \mathrm{~F}_{3}$ & 6DS.6DL-6PS & 6PS (0.81-1.00) \\
\hline WAT646 & Homozygous & $\mathrm{BC}_{2} \mathrm{~F}_{3}$ & 1BL·1BS-6PS & 6PS (0.86-1.00) \\
\hline WAT644 & Homozygous & $\mathrm{BC}_{2} \mathrm{~F}_{3}$ & 6PL·6PS-A & $6 \mathrm{PS}(0.00-0.20)+6 \mathrm{PL}$ \\
\hline
\end{tabular}

6P segment size: The comparison of the length of $6 \mathrm{P}$ segments and intact $6 \mathrm{P}$ arm. The position of the centromere was considered as 0 , while the terminal end of the 6PS/6PL arm was considered as 1 (Figure 6). The arm length was measured using the software image J [41] and the fraction length value was calculated as described by Endo and Gill [42].

\subsection{Molecular Cytogenetic Analysis}

Chromosome spreads of wheat-A. cristatum 6P translocation lines and A. cristatum 6P deletion lines from root tip cells were prepared as described by Han et al. [43]. GISH was carried out as described by Cuadrado et al. [44], except that the rinsing steps were modified with $0.5 \times$ saline sodium citrate instead of $0.1 \times$ saline sodium citrate. The A. cristatum "Z559" P-genomic DNA and common wheat "Fukuhokomugi" genomic DNA were respectively utilized as probe and block, at a 1:40 ratio. A. cristatum genomic DNA was labeled by DIG-Nick Translation Mix. DIG-Nick Translation Mix and 
anti-digoxigenin-rhodamine (red) were purchased from Roche, Mannheim, Germany. Signals were observed using an OLYMPUS AX80 (Olympus Corporation, Tokyo, Japan) fluorescence microscope. Images were captured with a CCD camera (Diagnostic Institute, Inc., Sterling Height, MI, USA) and processed with Photoshop CS 3.0.

P genome-specific markers and 6P-specific STS markers [30,32] were used to detect translocation lines and deletion lines. $\mathrm{P}$ genome-specific markers can trace the $\mathrm{P}$ genomic component in wheat background, which were designed through specific DNA sequences distributing the entire $\mathrm{P}$ genome [30]. Zhang et al. [32] designed the 6P-specific STS markers according to the EST sequences from A. cristatum transcriptome. Song et al. [30] mapped $2556 \mathrm{P}$-specific STS markers on the physical map using the deletion lines and translocation lines. We used 6P-specific STS markers to trace the different 6P segments of translocation lines and deletion lines.

\subsection{Evaluation of Stripe Rust Resistance at Adult Stage}

Homozygous materials and the $\mathrm{BC}_{2} \mathrm{~F}_{2}$ and $\mathrm{BC}_{3} \mathrm{~F}_{2}$ populations of WAT639a and WAT639b were planted in a random complete block design with three replicates in the fields of Yangling $\left(34^{\circ} 16^{\prime} 56.24^{\prime \prime} \mathrm{N}\right.$, $108^{\circ} 4^{\prime} 27.95^{\prime \prime}$ E, Shaanxi province, China) and Xinxiang ( $35^{\circ} 18^{\prime} 13.71^{\prime \prime}$ N, $113^{\circ} 55^{\prime} 15.05^{\prime \prime}$ E, Henan province, China) during 2015-2016 and 2016-2017. 4844-12, Fukuhokomugi and Huixianhong were used as controls, meanwhile Huixianhong was also used as the spreader rows. Twenty grains of each line were evenly planted in $2.0 \mathrm{~m}$ rows, spaced $0.3 \mathrm{~m}$ apart. A mixture of prevalent physiological races composed of CYR32 and CYR33 was used to infect plants at wheat elongation stage.

Host responses to infection were recorded when leaves of Huixianhong were fully rusted [45]. The infection type (IT) of each plant was recorded based on 0-9 rating scale, with 0 as immune (no visible signs), 1-2 as high resistance (no or few sporulation), 3-4 as intermediate resistance (trace sporulation), 5-6 as intermediate susceptibility (intermediate sporulation), 7-8 as susceptibility (abundant sporulation) and 9 as high susceptibility (no necrosis or chlorosis; abundant sporulation). Plants with IT 0-4 were considered resistant, while plants with IT 5-9 were considered susceptible.

\subsection{Statistical Analysis of Field Experiment}

Statistical Analysis System (Version 9.2, SAS Institute, Cary, NC, USA) was used for statistical analysis in this study. Plants in each population were classified to two types according to molecular marker analysis: plants with $P$ genome-specific markers and plants without $P$ genome-specific markers. Chi-squared $\left(\chi^{2}\right)$ tests for independence were used to determine the association between 6P segments and response to stripe rust.

The translocation lines were manually harvested at the maturity stage. We measured and counted the spike agronomic traits including spike length, spikelet number per spike, kernel number per spikelet, grain number per spike and thousand-grain weight. The analysis of variance was performed to test the difference between the translocation lines and the parent Fukuhokomugi in the agronomic traits.

Acknowledgments: This work was supported by the National Key Technology Support Program of China (No. 2013BAD01B02).

Author Contributions: Lihui Li and Weihua Liu conceived and designed the experiments. Zhi Zhang and Liqiang Song performed the experiments, collected data and wrote the paper. Zhi Zhang and Liqiang Song contributed equally to this work. Haiming Han and Shenghui Zhou analyzed data. Jinpeng Zhang, Xinming Yang and Xiuquan Li contributed reagents/materials/analysis tools. All authors commented and approved the final version.

Conflicts of Interest: The authors declare no conflict of interest. 


\section{Abbreviations}

$\begin{array}{ll}\text { GISH } & \text { Genomic in situ hybridization } \\ \text { STS } & \text { Sequence tagged sites } \\ \text { EST } & \text { Expressed sequence tag } \\ \text { DAPI } & \text { 4,6-diamino-2-phenyl indole } \\ \text { IT } & \text { Infection type } \\ \text { SAS } & \text { Statistical Analysis System }\end{array}$

\section{References}

1. Line, R.F. Stripe rust of wheat and barley in North America: A retrospective historical review. Annu. Rev. Phytopathol. 2002, 40, 75-118. [CrossRef] [PubMed]

2. Hovmøller, M.S.; Walter, S.; Justesen, A.F. Escalating threat of wheat rusts. Science 2010, 329, 369. [CrossRef] [PubMed]

3. Ma, D.; Hou, L.; Tang, M.S.; Wang, H.G.; Li, Q.; Jing, J.X. Genetic analysis and molecular mapping of a stripe rust resistance gene $Y r H 9014$ in wheat line H9014-14-4-6-1. J. Integr. Agric. 2013, 12, 638-645. [CrossRef]

4. Chen, X.M. Epidemiology and control of stripe rust [Puccinia striiformis f. sp. tritici] on wheat. Can. J. Plant Pathol. 2005, 27, 314-337. [CrossRef]

5. Wellings, C.R. Global status of stripe rust: A review of historical and current threats. Euphytica 2011, 179, 129-141. [CrossRef]

6. Sharma-Poudual, D.; Chen, X.M.; Wan, A.M.; Zhan, G.M.; Kang, Z.S.; Cao, S.Q.; Jin, S.L.; Morgounov, A.; Akin, B.; Mert, Z.; et al. Virulence characterization of international collections of the wheat stripe rust pathogen, Puccinia striiformis f. sp. tritici. Plant Dis. 2013, 97, 379-386. [CrossRef]

7. Singh, N.K.; Shepherd, K.W.; McIntosh, R.A. Linkage mapping of genes for resistance to leaf, stem, and stripe rusts and X-secalins on the short arm of rye chromosome 1R. Theor. Appl. Genet. 1990, 80, 609-616. [CrossRef] [PubMed]

8. Friebe, B.; Jiang, J.; Raupp, W.J.; McIntosh, R.A.; Gill, B.S. Characterization of wheat-alien translocations conferring resistance to diseases and pests: Current status. Euphytica 1996, 91, 59-87. [CrossRef]

9. Cao, A.; Xing, L.; Wang, X.; Yang, X.; Wang, W.; Sun, Y.; Qian, C.; Ni, J.; Chen, Y.; Liu, D. Serine/threonine kinase gene $S t p k-V$, a key member of powdery mildew resistance gene Pm21, confers powdery mildew resistance in wheat. Proc. Natl. Acad. Sci. USA 2011, 108, 7727-7732. [CrossRef] [PubMed]

10. Li, Q.; Huang, J.; Hou, L.; Liu, P.; Jing, J.; Wang, B.; Kang, Z. Genetic and molecular mapping of stripe rust resistance gene in wheat-Psathyrostachys huashanica translocation line H9020-1-6-8-3. Plant Dis. 2012, 96, 1482-1487. [CrossRef]

11. Dewey, D.R. The genomic system of classification as a guide to intergeneric hybridization with the perennial Triticeae. In Gene Manipulation in Plant Improvement; Gustafson, J.P., Ed.; Plenum Press: New York, NY, USA, 1984; pp. 209-279.

12. Dong, Y.C.; Zhou, R.H.; Xu, S.J.; Li, L.H.; Cauderon, Y.; Wang, R.R.C. Desirable characteristics in perennial Triticeae collected in China for wheat improvement. Hereditas 1992, 116, 175-178. [CrossRef]

13. Zhang, J.P.; Liu, W.H.; Han, H.M.; Song, L.Q.; Bai, L.; Gao, Z.H.; Zhang, Y.; Yang, X.; Li, X.; Gao, A.; et al. De novo transcriptome sequencing of Agropyron cristatum to identify available gene resources for the enhancement of wheat. Genomics 2015, 106, 129-136. [CrossRef] [PubMed]

14. Sharma, H.C.; Gill, B.S.; Uyemoto, J.K. High levels of resistance in Agropyron species to barley yellow dwarf and wheat streak mosaic viruses. J. Phytopathol. 1984, 110, 143-147. [CrossRef]

15. Wang, R.R.C. Agropyron and Psathyrostachys. In Wild Crop Relatives: Genomic and Breeding Resources, Cereals; Kole, C., Ed.; Springer-Verlag: Berlin/Heidelberg, Germany, 2011; pp. 77-108.

16. Ochoa, V.; Madrid, E.; Said, M.; Rubiales, D.; Cabrera, A. Molecular and cytogenetic characterization of a common wheat-Agropyron cristatum chromosome translocation conferring resistance to leaf rust. Euphytica 2015, 201, 89-95. [CrossRef]

17. Li, L.H.; Dong, Y.C.; Zhou, R.H.; Li, X.Q.; Li, P. Cytogenetics and self-fertility of hybrids between Triticum aestivum L. and Agropyron cristatum (L.) Gaertn. Acta Genet. Sin. 1995, 22, 109-114.

18. Li, L.H.; Li, X.Q.; Li, P.; Dong, Y.C.; Zhao, G.S. Establishment of wheat-Agropyron cristatum alien addition lines. I. Cytology of $\mathrm{F}_{3}, \mathrm{~F}_{2} \mathrm{BC}_{1}, \mathrm{BC}_{4}$, and $\mathrm{BC}_{3} \mathrm{~F}_{1}$ progenies. Acta Genet. Sin. 1997, 24, 154-159. 
19. Limin, A.E.; Fowler, D.B. An interspecific hybrid and amphiploid produced from Triticum aestivum crosses with Agropyron cristatum and Agropyron desertorum. Genome 1990, 33, 581-584. [CrossRef]

20. Wu, J.; Yang, X.M.; Wang, H.; Li, H.J.; Li, L.H.; Li, X.Q.; Liu, W.H. The introgression of chromosome 6P specifying for increased numbers of florets and kernels from Agropyron cristatum into wheat. Theor. Appl. Genet. 2006, 114, 13-20. [CrossRef] [PubMed]

21. Lu, M.J.; Lu, Y.Q.; Li, H.H.; Pan, C.L.; Guo, Y.; Zhang, J.P.; Yang, X.M.; Li, X.Q.; Liu, W.H.; Li, L.H. Transferring Desirable Genes from Agropyron cristatum 7P Chromosome into Common Wheat. PLoS ONE 2016, 11, e0159577. [CrossRef] [PubMed]

22. Li, H.H.; Jiang, B.; Wang, J.C.; Lu, Y.Q.; Zhang, J.P.; Pan, C.L.; Yang, X.M.; Li, X.Q.; Liu, W.H.; Li, L.H. Mapping of novel powdery mildew resistance gene(s) from Agropyron cristatum chromosome 2P. Theor. Appl. Genet. 2017, 130, 109-121. [CrossRef] [PubMed]

23. Copete, A.; Cabrera, A. Chromosomal location of genes for resistance to powdery mildew in Agropyron cristatum and mapping of conserved orthologous set molecular markers. Euphytica 2017, 213, 189. [CrossRef]

24. Qi, L.L.; Wang, S.L.; Chen, P.D.; Liu, D.J.; Gill, B.S. Identification and physical mapping of three Haynaldia villosa chromosome-6V deletion lines. Theor. Appl. Genet. 1998, 97, 1042-1046. [CrossRef]

25. Ashida, T.; Nasuda, S.; Sato, K.; Endo, T.R. Dissection of barley chromosome $5 \mathrm{H}$ in common wheat. Genes Genet. Syst. 2007, 82, 123-133. [CrossRef] [PubMed]

26. Song, L.Q.; Lu, Y.Q.; Zhang, J.P.; Pan, C.L.; Yang, X.M.; Li, X.Q.; Liu, W.; Li, L. Physical mapping of Agropyron cristatum chromosome 6P using deletion lines in common wheat background. Theor. Appl. Genet. 2016, 129, 1023-1034. [CrossRef] [PubMed]

27. Luan, Y.; Wang, X.G.; Liu, W.H.; Li, C.Y.; Zhang, J.P.; Gao, A.N.; Wang, Y.; Yang, X.; Li, L. Production and identification of wheat-Agropyron cristatum 6P translocation lines. Planta 2010, 232, 501-510. [CrossRef] [PubMed]

28. Song, L.Q.; Jiang, L.L.; Han, H.M.; Gao, A.N.; Yang, X.M.; Li, L.H.; Liu, W.H. Efficient induction of wheat-Agropyron cristatum 6P translocation lines and GISH detection. PLoS ONE 2013, 8, e69501. [CrossRef] [PubMed]

29. Song, L.Q.; Lu, Y.Q.; Zhang, J.P.; Pan, C.L.; Yang, X.M.; Li, X.Q.; Liu, W.H.; Li, L.H. Cytological and molecular analysis of wheat-Agropyron cristatum translocation lines with $6 \mathrm{P}$ chromosome fragments conferring superior agronomic traits in common wheat. Genome 2016, 59, 840-850. [CrossRef] [PubMed]

30. Han, H.M.; Liu, W.H.; Lu, Y.Q.; Zhang, J.P.; Yang, X.M.; Li, X.; Hu, Z.; Li, L. Isolation and application of P genome-specific DNA sequences of Agropyron Gaertn. in Triticeae. Planta 2017, 245, 425-437. [CrossRef] [PubMed]

31. Jiang, J.; Friebe, B.; Gill, B.S. Recent advances in alien gene transfer in wheat. Euphytica 1994, 73, $199-212$. [CrossRef]

32. Zhang, J.P.; Liu, W.H.; Lu, Y.Q.; Liu, Q.; Yang, X.; Li, X.; Li, L. A resource of large-scale molecular markers for monitoring Agropyron cristatum chromatin introgression in wheat background based on transcriptome sequences. Sci. Rep. 2017, 7, 11942. [CrossRef] [PubMed]

33. Wan, A.M.; Zhao, Z.H.; Chen, X.M.; He, Z.; Jin, S.; Jia, Q.; Yao, G.; Yang, J.; Wang, B.; Li, G.; et al. Wheat stripe rust epidemic and virulence of Puccinia striiformis f. sp. tritici in China in 2002. Plant Dis. 2004, 88, 896-904. [CrossRef]

34. Wan, A.M.; Chen, X.M.; He, Z.H. Wheat stripe rust in China. Aust. J. Agric. Res. 2007, 58, 605-619. [CrossRef]

35. Chen, W.Q.; Wu, L.R.; Liu, T.G.; Xu, S.C.; Jin, S.L.; Peng, Y.L.; Wang, B.T. Race dynamics diversity, and virulence evolution in Puccinia striiformis $\mathrm{f}$. sp. tritici, the causal agent of wheat stripe rust in China from 2003 to 2007. Plant Dis. 2009, 93, 1093-1101. [CrossRef]

36. Liu, J.; Chang, Z.J.; Zhang, X.J.; Yang, Z.; Li, X.; Jia, J.; Zhan, H.; Guo, H.; Wang, J. Putative Thinopyrum intermedium-derived stripe rust resistance gene Yr50 maps on wheat chromosome arm 4BL. Theor. Appl. Genet. 2013, 126, 265-274. [CrossRef] [PubMed]

37. Jauhar, P.P.; Peterson, T.S.; Xu, S.S. Cytogenetic and molecular characterization of a durum alien disomic addition line with enhanced tolerance to Fusarium head blight. Genome 2009, 52, 467-483. [CrossRef] [PubMed]

38. Gerechter-Amitai, Z.; Van Silfhout, C.; Grama, A.; Kleitman, F. Yr15-a new gene for resistance to Puccinia striiformis in Triticum dicoccoides sel. G-25. Euphytica 1989, 43, 187-190. [CrossRef] 
39. Dadkhodaie, N.; Karaoglou, H.; Wellings, C.; Park, R. Mapping genes Lr53 and Yr35 on the short arm of chromosome 6B of common wheat with microsatellite markers and studies of their association with Lr36. Theor. Appl. Genet. 2011, 122, 479-487. [CrossRef] [PubMed]

40. McFadden, E.S. A successful transfer of emmer characters to vulgare wheat. J. Am. Soc. Agron. 1930, 22, 1020-1034. [CrossRef]

41. Schneider, C.A.; Rasband, W.S.; Eliceiri, K.W. NIH image to imageJ: 25 years of image analysis. Nat. Methods 2012, 9, 671-675. [CrossRef] [PubMed]

42. Endo, T.R.; Gill, B.S. The deletion stocks of common wheat. J. Hered. 1996, 87, 295-307. [CrossRef]

43. Han, F.P.; Lamb, J.C.; Birchler, J.A. High frequency of centromere inactivation resulting in stable dicentric chromosomes of maize. Proc. Natl. Acad. Sci. USA 2006, 103, 3238-3243. [CrossRef] [PubMed]

44. Cuadrado, A.; Schwarzacher, T.; Jouve, N. Identification of different chromatin classes in wheat using in situ hybridization with simple sequence repeat oligonucleotides. Theor. Appl. Genet. 2000, 101, 711-717. [CrossRef]

45. Roland, F.L.; Abdul, Q. Collecting and Evaluating Rust Samples for Virulence. In Virulence, Aggressiveness, Evolution, and Distribution of Races of Puccinia striiformis (the Cause of Stripe Rust of Wheat) in North America, 1968-87; U.S. Department of Agriculture: Washington, DC, USA, 1992; pp. 4-9.

(C) 2017 by the authors. Licensee MDPI, Basel, Switzerland. This article is an open access article distributed under the terms and conditions of the Creative Commons Attribution (CC BY) license (http:/ / creativecommons.org/licenses/by/4.0/). 